\section{Eosinophilic Esophagitis: Treatment With Different Doses of Omeprazole in Children Under 16 Years}

Gómez Torrijos E ${ }^{1}$, Donado Palencia $\mathrm{P}^{2}$, Sanchez Miranda $\mathrm{MP}^{2}$, Moreno Lozano L ${ }^{1}$, Extremera Ortega $\mathrm{AM}^{1}$, Borja Segade $\mathrm{JM}^{1}$, Galindo Bonilla PA ${ }^{1}$, García Rodríguez $\mathrm{R}^{1}$

${ }^{\prime}$ Allergology Service, Hospital General Universitario de Ciudad Real, Ciudad Real, Spain

${ }^{2}$ Pediatric Gastroenterology Pediatric, Hospital General Universitario de Ciudad Real, Ciudad Real, Spain

J Investig Allergol Clin Immunol 2018; Vol. 28(3): 191-192 doi: 10.18176/jiaci.0230

Key words: Eosinophilic esophagitis. Omeprazole. Children. Teenager. Eosinophils.

Palabras clave: Esofagitis eosinofílica. Omeprazol. Niños. Adolescentes. Eosinófilos.

Treatment of eosinophilic esophagitis (EoE) in children and adults is similar [1], although it is not always easy for the physician to choose the best therapeutic modality in patients aged $<16$ years.

It is widely accepted that treatment of EoE can start with proton pump inhibitors (PPIs), with corticosteroids, or with elimination diets. Some experts advise treating EoE with PPIs, as they are well tolerated and adverse effects are minimal. In addition, many patients respond to high doses of PPIs, with no significant differences in patient age, study design, or type of PPI assessed [1,2]. The objectives of our study were to calculate the proportion of patients with EoE who experienced clinical and histological remission with high doses of PPIs ( $\leq 40 \mathrm{~kg}$, omeprazole at $1 \mathrm{mg} / \mathrm{k} / 12 \mathrm{~h}$ for 2 months; $>40 \mathrm{~kg}$, omeprazole at $40 \mathrm{mg} / 12 \mathrm{~h}$ for 2 months) in order to determine which patients with EoE responded to PPIs, assess the persistence of remission when the dose of omeprazole is reduced by half, and evaluate possible adverse effects of omeprazole during the first 6 months of therapy.

We performed a prospective, descriptive study of 40 patients aged $<16$ years who were assessed in a specialized EoE clinic from 2011 to 2016 because of symptoms of esophageal dysfunction or swallowing disorders. The patients underwent esophagogastroduodenoscopy with biopsy specimens taken from different sections of the esophagus and other organs. Patients were diagnosed with EoE if they had at least $15 \mathrm{eos} / \mathrm{hpf}$ in the esophagus and had no eosinophils in the stomach or in the duodenum. We recommended treatment with high doses of PPIs, but only 34 patients adhered to treatment. We studied the proportion of patients who responded to $1 \mathrm{mg} / \mathrm{k} / \mathrm{d}$ of omeprazole, which was administered in 2 doses in children weighing $\leq 40 \mathrm{~kg}$; in patients weighing more than $40 \mathrm{~kg}$, the prescribed dose was $80 \mathrm{mg} / \mathrm{d}$, for at least 2 months. Nonresponse to treatment with PPIs was defined as at least 15 eos/hpf [1,2]. During the first 6 months of treatment with omeprazole, patients were reviewed every 2 months and asked about possible adverse effects of omeprazole.

Nine patients responded to treatment with high doses of omeprazole. Three patients experienced adverse effects due to omeprazole (8.3\%). In the case of Patient 1 ( $\geq 60 \mathrm{mg} / \mathrm{d}), \mathrm{EoE}$ remitted but left the patient with asymptomatic esophageal candidiasis. Patient $2(40 \mathrm{mg} / \mathrm{d})$ started with diplopia, which resolved 1 week after withdrawal. Patient 3 experienced diarrhea

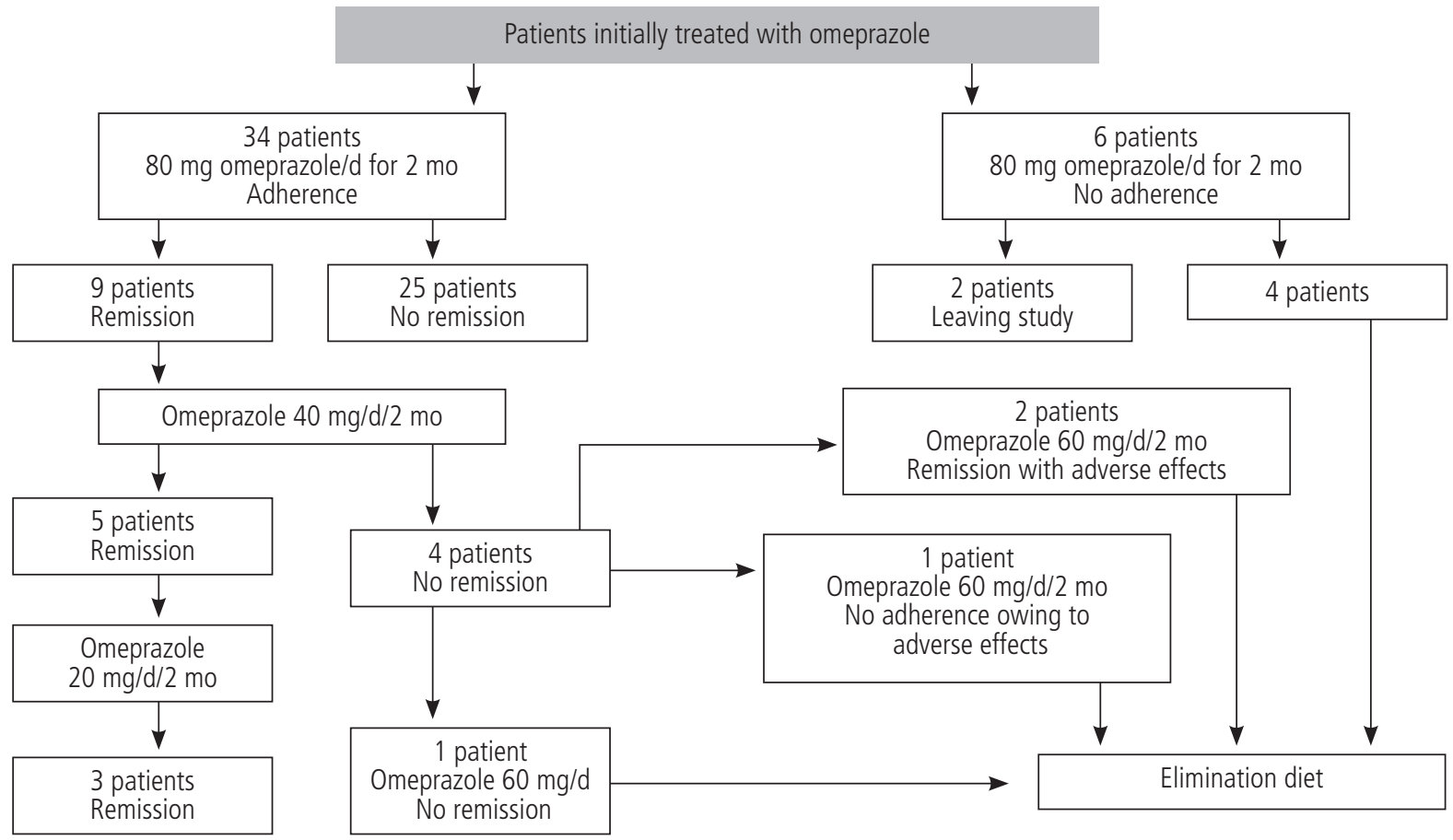

Figure. Patients initially treated with omeprazole. 
after 1 month, thus forcing us to withdraw omeprazole (Figure).

It is widely accepted that active EoE should be treated. Any treatment applied should ideally achieve 2 therapeutic goals: first, resolution of symptoms, and, second, control of inflammation [3].

PPI-responsive esophageal eosinophilia is considered by some experts to be a subtype of EoE [1], since the only difference with EoE is that it responds to treatment with PPIs [4].

The term PPI-responsive esophageal eosinophilia is an inappropriate description of the disease, since it is arbitrarily based on the response to a single drug and should longer be used. PPI monotherapy effectively downregulates $\mathrm{T}_{\mathrm{H}} 2$ mediated inflammation and normalizes gene expression associated with EoE in a similar way to that observed for topical corticosteroids [5].

The response of EoE to PPIs has been well studied in adults and children $[1,2]$; however, depending on the studies consulted, remission may be less frequent in children than in adults $[1,2,6]$.

Despite the lack of expert consensus on whether PPIs should be the first-line treatment in EoE [4,7], we began treatment with omeprazole because it is well-tolerated, has few adverse effects, and induces clinical and histological remission of the disease in up to half of patients [1,2]. In the children in the present study, remission was much lower after treatment with high-dose PPIs than in a previously published study, in which $68 \%$ of patients achieved remission after treatment with esomeprazole, with sustained remission in $78 \%$ after lowering the dose by half [8]. In contrast, our results are much worse and may be explained by the use of different PPIs. Our results are closer to those of Molina-Infante et al [6], who reported remission rates of $23 \%-40 \%$ [6].

In EoE that responds to PPI, it is important to study the minimum dose necessary to induce clinical and histological remission, since this requires long-term anti-inflammatory treatment, which predisposes to potential adverse effects. To date, adverse effects have not been reported after 6 months of treatment with PPIs in patients with EoE; however, adverse effects have been reported in patients with a 10 year history of gastroesophageal reflux disease (GERD) [9] and are more frequent in GERD (34\%) than in EoE (8.3\%). Other adverse effects include visual alterations, especially blurred vision. One of the patients we report had diplopia (an unusual visual alteration), which we were able to confirm as occurring secondary to treatment with omeprazole, because it disappeared after withdrawal and has not reoccurred in 2 years.

We previously performed a similar study in adult patients and found that remission was more frequent in adults $(33 \%)$ than in children and adolescents (26.5\%)

EoE is currently considered to be a chronic health condition whose increasing prevalence is generating a significant health care burden [10] and forcing physicians to place emphasis on improving or maintaining adherence.

We conclude that omeprazole is a valid option in EoE, at least in the short term. However, adherence to treatment is crucial if remission is to be maintained. The physician can improve or maintain adherence by taking into account patient preferences for the different types of treatment. It is important to study the minimum dose of PPIs that keeps EoE in remission in order to improve adherence and decrease the likelihood of adverse effects.

\section{Funding}

The authors declare that no funding was received for the present study.

\section{Conflicts of Interest}

The authors declare that they have no conflicts of interest.

\section{References}

1. Gonzalez-Cervera J, Lucendo AJ. Eosinophilic esophagitis. J Investig Clin Immunol 2016;26:8-18.

2. Lucendo AJ, Molina-Infante J,Arias Á, von Arnim U, Bredenoord AJ, Bussmann C, et al. Guidelines on eosinophilic esophagitis: evidence-based statements and recommendations for diagnosis and management in children and adults. United European Gastroenterol J. 2017:5(3):335-58.

3. Straumann A. Medical therapy in eosinophilic oesophagitis. Best Pract Res Clin Gastroenterol. 2015;29:805-14.

4. Molina-Infante J, Bredenoord AJ, Cheng E, Dellon ES, Furuta GT, Gupta SK, et al. Proton pump inhibitor-responsive oesophageal eosinophilia: an entity challenging current diagnostic criteria for eosinophilic oesophagitis. Gut. 2016;65:524-31.

5. Molina-Infante J, Lucendo AJ. Proton Pump Inhibitor Therapy for Eosinophilic Esophagitis: A Paradigm Shift. Am J Gastroenterol. 2017;112(12):1770-3.

6. Molina-Infante J, Katzka DA, Gisbert JP. Review article: proton pump inhibitor therapy for suspected eosinophilic oesophagitis. Aliment Pharmacol Ther. 2013;37:1157-64.

7. Muir AB, Wang ML, Metz D, Falk G, Markowitz J, Spergel $J M$, et al. Proton pump inhibitor-responsive oesophageal eosinophilia: too early to change clinical practice. Gut. 2017;66(5):979-80.

8. Gutiérrez-Junquera $C$, Fernández-Fernández $S$, Cilleruelo ML, Rayo A, Echeverría L, Quevedo S, et al. High prevalence of response to proton pump inhibitor treatment in children with esophageal eosinophilia. J Pediatr Gastroenterol Nutr. 2016;62:704-10.

9. Cohen S, Bueno de Mesquita M, Mimouni FB. Adverse effects reported in the use of gastroesophageal reflux disease treatments in children: a 10 years literature review. $\mathrm{Br} J$ Clin Pharmacol. 2015;80(2):200-8.

10. Gómez Torrijos E, Sánchez Miranda P, Donado Palencia P, Castro Jimenez A, Rodriguez Sánchez J, Mendez Díaz Y, et al. Eosinophilic Esophagitis: Demographic, Clinical, Endoscopic, Histologic, and Atopic Characteristics of Children and Teenagers in a Region in Central Spain. J Investig Allergol Clin Immunol. 2017;27(2):104-10.

- Manuscript received December 4, 2017; accepted for publication January 12, 2018.

Elisa Gomez Torrijos

General Universitario de Ciudad Real C/ Obispo Rafael Torija, s/n

13005 Ciudad Real, Spain E-mail: egomezt.cr@gmail.com 